\title{
Attempted Reconstruction of the Cortico-Striatal Pathway Using Fetal Cortical Tissue Transplants
}

\author{
A.S. Herranz, H.E. Cannon-Spoor and W.J. Freed \\ NIMH Neuroscience Center at St. Elizabeths, Washington D.C. 20032, USA
}

Brain grafting techniques have been developed for the transplantation of neural tissue, including cerebral cortex, into adult CNS (Labbe et al., Science 1983; 221: 470-472; Castro et al., Neurosci Lett 1985; 60: 164-166; Dunnett et al., Behav Neurosci 1987; 110: 498-503; Heredia et al., J. Neurosci Meth 1991; 36: 17-25). Grafts have been shown to survive and to establish reciprocal connections with the host brain. Injury to both central and peripheral nervous systems has been hypothesized to result in the release of substances which support the in vitro survival of neurons in tissue culture, as well as survival of embryonic brain grafts which are transplanted into previously injured CNS sites. The release of injury-induced neurotrophic and/or growth factors may be associated with observed reafferentation of the host brain. The feasibility of using fetal cortical tissue transplants to reconstruct the cortico-striatal system in adult rats which had previously received aspiration lesions of the cortex was investigated.

Adult rats were lesioned by aspiration of the prefrontal cortex. Lesions were made approximately from $3 \mathrm{~mm}$ anterior to the bregma to 3.5 $\mathrm{mm}$ posterior to the bregma and extended laterally into the parietal cortex approximately 2.5$3.0 \mathrm{~mm}$ (G Paxinos and C. Watson, The Rat Brain in Stereotaxic Coordinates, 2nd Edition). After 15 days, the lesioned rats were implanted with grafts of cortical tissue from E16 rat fetuses into the lesion cavity. Six weeks after fetal tissue grafts, the animals were sacrificed and the connectivity of the grafts with the host striatum evaluated. Five brains were cut in $3 \mathrm{~mm}$ slices and carbocyanine Dil was injected into the grafts using a micromanipulator.

Fifty mg of carbocyanine Dil was dissolved in $500 \mu \mathrm{l} \mathrm{N}, \mathrm{N}$-dimethylformamide and drawn up into a $1 \mu$ l Hamilton syringe. The syringe was lowered in the center of the graft to a depth of $1.5 \mathrm{~mm}$ below the surface of the tissue slices and $0.04 \mu \mathrm{l}$ of Dil solution was injected. The brains were left at $37^{\circ} \mathrm{C}$ for 2 weeks, followed by 2 weeks of refrigeration at $4^{\circ} \mathrm{C}$. After 2 days of immersion in a $30 \%$ sucrose solution, the brains were frozen and sectioned at $30 \mu \mathrm{m}$ for microscopic inspection.

Nine brains were immunostained for neurofilaments using the antibodies SMI-31 and SMI-35. Brains were evaluated for the number of fibers crossing the graft-host interface and the length of graft-host interface. In the Dil brains depth of penetration of fibers into the host caudateputamen was also measured. Three sections were studied per animal and mean values calculated. Depth of fiber penetration and length of graft-host interface were measured using the NIH Image 1.432 software for the Macintosh.

Dil tracing demonstrated graft-derived neurites (mean $31.0 \pm 5.9$ S.E.M.) penetrating into the host caudate-putamen. A few fibers penetrated a considerable distance into the host; the mean depth of penetration was $1.21 \pm 0.2 \mathrm{~mm}$ (range 0.56-2.06 mm). SMI-31 and SMI-35 immunoreactive neurites were frequently found crossing the interface with the corpus callosum and striatum $(11.5 \pm 2.2$ and $13.7 \pm 1.9$ per mm of interface, respectively), but only rarely entering the adjacent cortex.

It was concluded that: 1 . Fetal cortical grafts survive when placed in previously lesioned adult brains. 2. Fetal cortical grafts send limited projections into the denervated host caudateputamen and possibly may partially reconstruct the cortico-striatal pathway. 3 . Use of the carbocyanine Dil anterograde tracer in solution form can allow for accurate and reproducible placement of the tracer as well as volume delivered. 

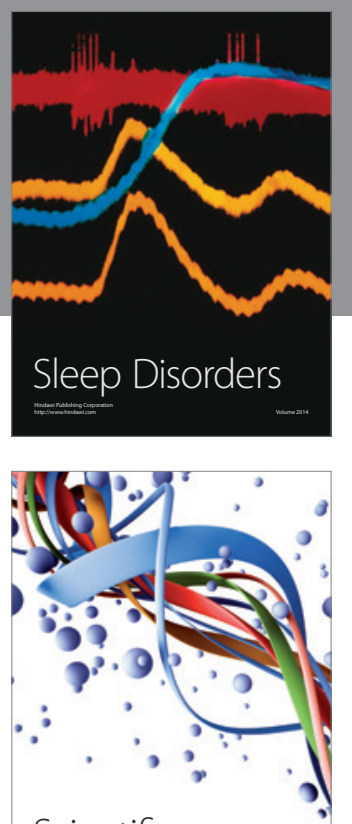

Scientifica
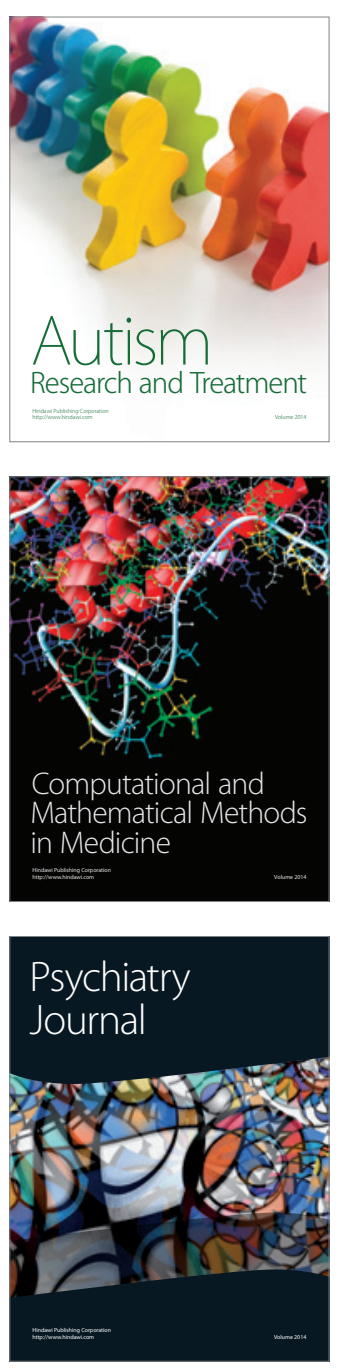
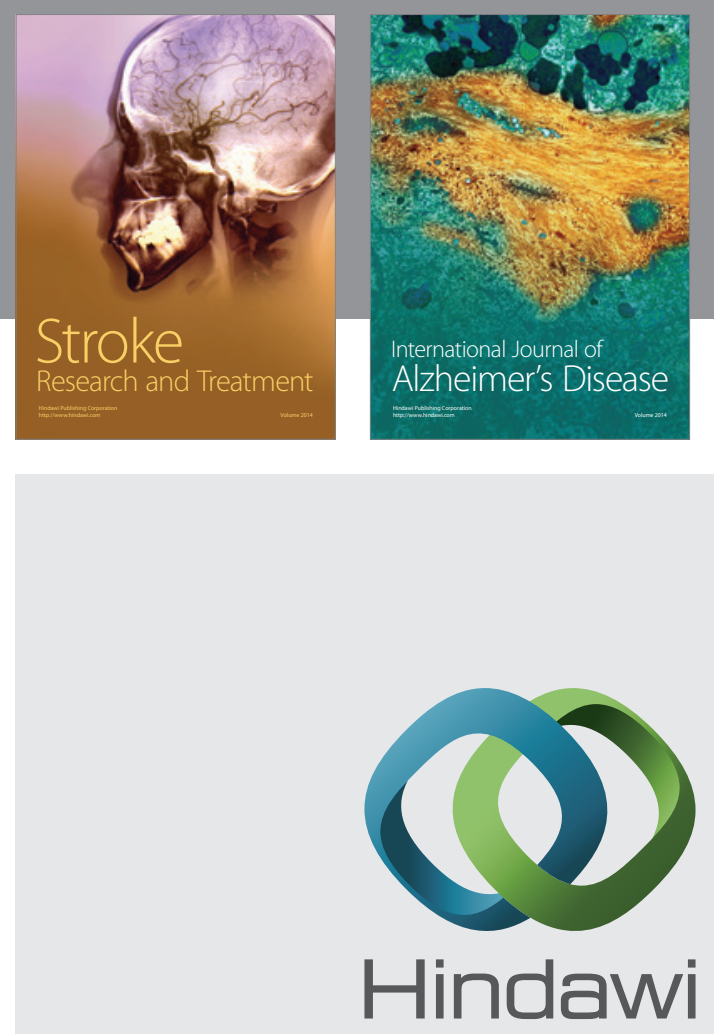

Submit your manuscripts at

http://www.hindawi.com
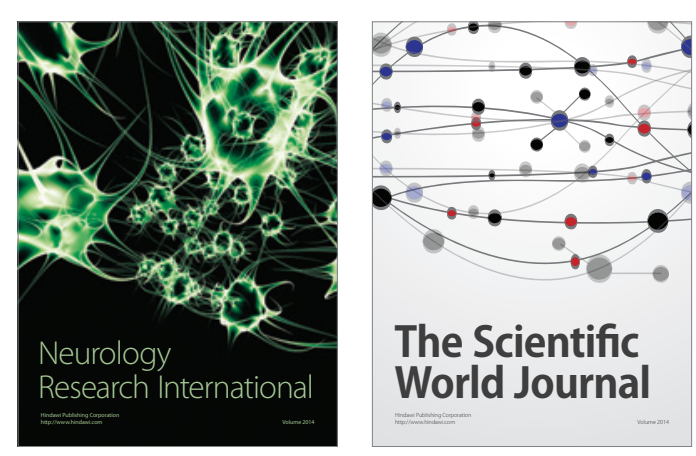

The Scientific World Journal

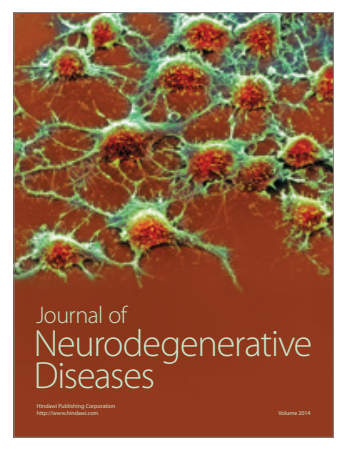

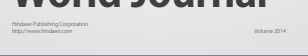

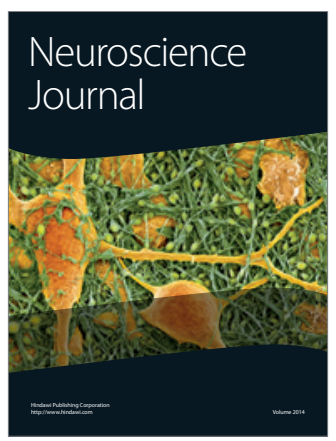

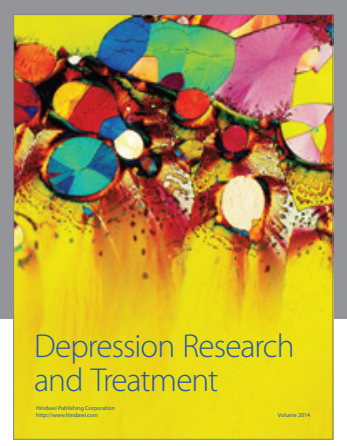
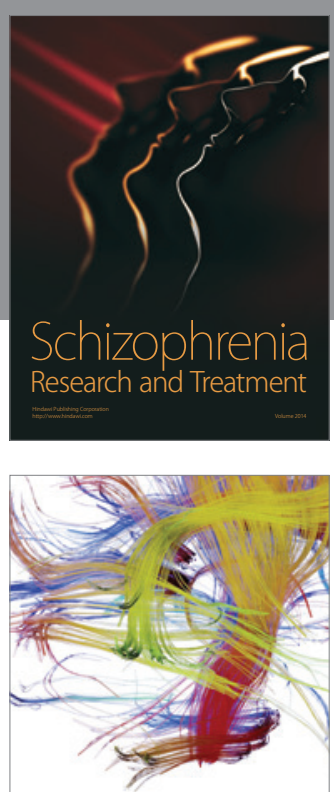

Brain Science

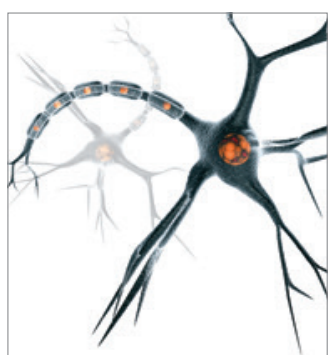

Neural Plasticity
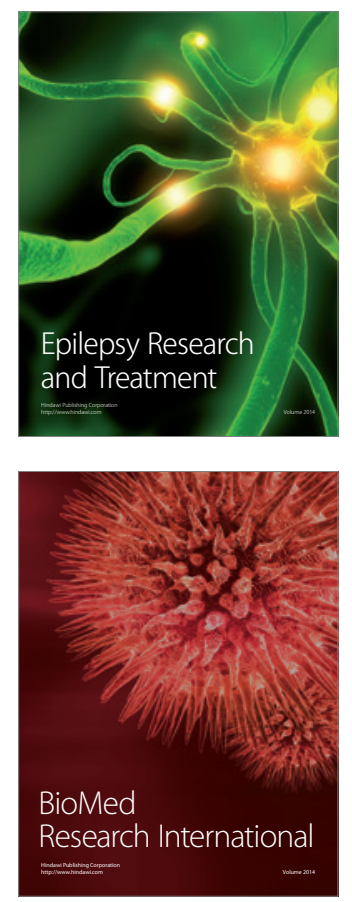

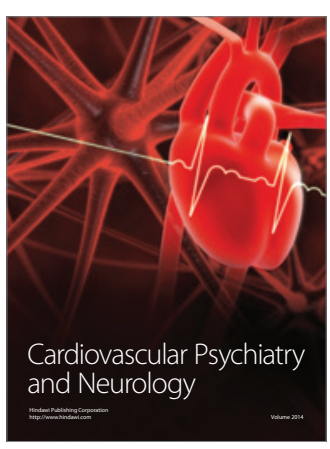

Parkinson's

Disease
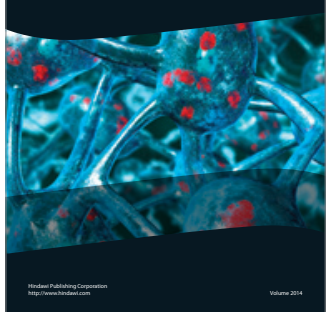